\title{
Corrosion of titanium implants and connected prosthetic alloys using lactic acid immersion test
}

\begin{abstract}
Background/purpose: Combination of dental titanium implants with other prosthetic metallic components may lead to metal ion release that increases the risk of adverse reactions in patients. The present study therefore aimed to determine in vitro metal ion dissolution from different alloy combinations.

Materials and methods: Dental alloys were subjected to a lactic acid immersion test together with titanium implants and matched with controls. Between day 1 and 38, open direct current potentials (DCP) between the samples and the electrolyte were recorded and metal dissociation inside the electrolyte was assessed using ICP-MS.

Results: Absolute DCPs of the different alloys increased significantly $(\mathrm{p}<0.001)$ from $100-150 \mathrm{mV}$ to $490-580 \mathrm{mV}$ within the first two weeks of immersion, dropping to about $450 \mathrm{mV}$ later on largely independent of the material. Titanium showed highest dissociation rates $\left(2.00-12.06 \mu \mathrm{g} / \mathrm{cm}^{2}\right.$ per day; $\left.\mathrm{p}=0.0002\right)$; all other components demonstrated poor corrosive dissolution $\left(<0.6 \mu \mathrm{g} / \mathrm{cm}^{2}\right.$ per day). After immersion of 38 days, titanium still yielded high dissociation $(0.64-1.38 \mu \mathrm{g} /$ $\mathrm{cm}^{2}$ per day) for all test groups. Presence of fine gold inside the electrolyte significantly increased dissociation of titanium $(p=0.027)$. Dissociation of iron indicated contamination from tool components used for implant production. Optical examination of non-precious metal surfaces showed no corrosive discoloration after 5 or 26 weeks of lactic acid immersion.
\end{abstract}

Conclusion: Within the limitations of this study, there is no objection against the use of non-precious alloys for the fabrication of components and prostheses supported on titanium implants if gold is not present inside the same electrolyte.

Keywords: corrosion, oral galvanism, dental alloys, titanium, lactic acid immersion, ICP-MS
Volume II Issue 3 - 2020

\author{
Wilhelm Niedermeier,' Katrin Huesker ${ }^{2}$ \\ 'Department of Prosthetic Dentistry, School for Dental and \\ Oral Medicine, University of Cologne, Germany \\ ${ }^{2}$ Department of Immuno-Toxicology, Institute for Medical \\ Diagnostics (IMD), Germany
}

Correspondence: Wilhelm Niedermeier, School for Dental and Oral Medicine, University of Cologne, Kerpener Str. 32, D-5093 I Cologne, Germany, Tel +4922147896746, Fax +4922147896756, Email wilh.niedermeier@uni-koeln.de

Received: June 06, 2020 | Published: June 23, 2020

\begin{abstract}
Abbreviations: DCP, direct current potentials; MEA, multielement-analysis
\end{abstract}

\section{Introduction}

Osseointegrated implants are a benefit for reconstructive dentistry. ${ }^{1}$ Among all materials used for the fabrication of dental implants, titanium is still first choice because of its stability, easy processing and biological acceptance. Nevertheless, titanium is a metal and therefore, it is prone to corrosion and possible biologic incompatibility, particularly in the case of combination with other metals or alloys. The risk of dissociation of metallic structures increases with the number of different metals and the difference of their electrochemical potential. Thereby, the position inside the electrochemical series of metals indicatesthe corrosive properties of the single elements. Among the commonly used components of dental alloys, corrosive potentials of non-precious metals like chromium $(-0.74 \mathrm{~V})$, titanium $(-0.34 \mathrm{~V})$, cobalt $(-0.28 \mathrm{~V})$ and molybdenum $(-0.20 \mathrm{~V})$ significantly differ from gold (between +1.4 and $+1.69 \mathrm{~V}$, according to its oxidation state). Considering this, there must be a smaller affinity to dissolution among non-precious metals themselves when they are combined in electrolyte solution. On the other hand, gold with its high redox potential is able to interfere with non-precious metals in order to generate corrosive processes at their surfaces. ${ }^{2}$
Biologic incompatibility against metallic substances does not appear before single metallic components are dissociated to ions which react with proteins in order to cause an allergic reaction, if a specific allergic predisposition exists in an individual. ${ }^{3,4}$ This can be one of the reasons for denture incompatibility and associated symptoms. ${ }^{5}$ Besides, electric fields generated by DC potentials (DCPs) of different metals or alloys can lead to cell reactions inside the oral cavity like apoptosis, proliferation, inflammation and leukoplakia..$^{6-9}$

On the other hand, abutments and dentures supported on dental implants must have considerable stability in order to tolerate masticatory forces. Specially in cases of implant supported freeend prostheses, high flexural fatigue strength must be provided that is not sufficiently ensured utilising gracile non-metallic or titanium abutments and denture components. ${ }^{10}$ Also, surface properties of titanium favour accumulation of biofilms compared to other nonprecious dental alloys. ${ }^{11}$ In addition, it can no longer remain unheeded that pure titanium as well as its alloys show a rather high rate of corrosion which can harm the surrounding peri-implant tissues and lead to systemic problems. ${ }^{12,13}$

Since implant supported full titanium dentures revealed diverse material faults, this study aimed to clarify the risk of corrosion resulting from a combined use of titanium implants and different dental alloys with the help of in vitro tests. 


\section{Materials and methods}

\section{Test groups}

Each 5 dental implants assembled with the itemized abutment systems were objected to 4 test groups:

Ti-Ti Titanium abutment (SiM $24^{\circ}$ angulated titanium base and SiM 5 cone 00307144) connected with titanium fixture using a titanium screw (PS 22).

Ti-Ti\& Au Titanium abutment ( $\mathrm{SiM} 24^{\circ}$ angulated titanium base and SiM 5 cone 00307144) connected with titanium fixture using a titanium screw (PS 22) and separate fine gold sample.

Ti-CCM Titanium abutment ( $\mathrm{SiM} 24^{\circ}$ angulated titanium base and SiM 5 cone 00307144 out of cobalt-chromium-molybdenum alloy $=\mathrm{CCM}$ ) connected with titanium fixture using a titanium screw (PS 22).

Ti-CCM \& Au Titanium abutment (SiM $24^{\circ}$ angulated titanium base and SiM 5 cone 00307144 out of CCM alloy) connected with titanium fixture using a titanium screw (PS 22)and separate fine gold sample.

\section{Metals and alloys}

All fixtures had a diameter of $4 \mathrm{~mm}$ and a length of $12 \mathrm{~mm}$ (BredentblueSKY ${ }^{\circledR}$, bSKY4012: Bredent, Ulm, Germany) and were fabricated out of titanium grade 4 (ISO 5832-2, Klein SA, Biel/ Bienne, Switzerland). Two-piece angulated abutments were out of titanium grade 4 (ISO 5832-2, Klein SA, Biel/Bienne, Switzerland). CCM-SiM 5 cones were specially fabricated for this study as a copy of the serial titanium part SiM 5 cone, and were made out of CCM alloy (Co-Cr28-Mo, MicroMelt ${ }^{\mathbb{B}}$, Klein SA, Biel/Bienne, Switzerland). All abutment connection screws were out of titanium grade 4 (ISO 58322, Klein SA, Biel/Bienne, Switzerland). ${ }^{10}$

Fine gold samples (Au 999.9, Degussa, Hanau, Germany) with a size of $16 \times 14 \mathrm{~mm}$ and a thickness of $0.5 \mathrm{~mm}$ were ground superficially using metal-free diamond paper with a roughness of 800 (Telum ${ }^{\circledR}$ K 800, Karl Sommer, Loebau, Germany) to achieve equal surface quality.

\section{Corrosion assay set-up}

In order to mimic the clinical situation and to standardise the parameters in vitro, the lactic acid immersion test according to DIN EN ISO $10271^{14}$ was applied as the best available testto investigate corrosive properties of the different metallic components; this test is generally regarded the relevant standard to studyin-vitro corrosionof metallic materials in dentistry. ${ }^{13,14}$

To achieve a clean and metal-free test environment, all samples, glass tanks, silicone hose pipes and plastic tweezers used in the experimental set-up were separately cleaned up using ultrasonic bath and a neutral cleansing agent, and were rinsed with pure water (aqua bidest.: Braun, Melsungen, Germany) for $5 \times 3 \mathrm{~min}$.

The fixtures were placed inside a silicone hose pipe covering the entire osseointegration surface up to $-0.5 \mathrm{~mm}$ marginal height and were sealed with silicone glue at the apical end (Figure 1). This procedure should imitate an end osseous implant bed during electrochemical processes. A preliminary test showed that this "pseudoosseo integrated surface" emitted only a part of about $15-20 \%$ of corrosion products compared to the non-covered surface. This effect was factored accordingly in calculating the corrosive surface of the samples (Table 1).

Table I Sample surfaces inclusive pseudo-osseointegrated areas as well as ratio between electrolyte volume and sample surface; abbreviations see in "materials and methods, ff: test groups"

\begin{tabular}{|c|c|c|c|c|c|c|}
\hline \multirow[t]{2}{*}{ Test series } & \multicolumn{3}{|c|}{$\begin{array}{l}\text { Surface }\left(\mathrm{mm}^{2}\right) \text { of samples inclusive "osseointegrated" } \\
\text { areas } x 0.175\end{array}$} & \multicolumn{3}{|c|}{ Electrolyte volume/sample surface $\left(\mathrm{ml} / \mathrm{mm}^{2}\right)$} \\
\hline & $\mathrm{Ti}$ & $\mathrm{CCM}$ & $\mathrm{Au}$ & $\mathrm{Ti}$ & CCM & $\mathrm{Au}$ \\
\hline $\mathrm{Ti}-\mathrm{Ti}$ & 210.8 & & & 0.237 & & \\
\hline Ti-Ti\& Au & 210.8 & & 478 & 0.237 & & 0.105 \\
\hline Ti-CCM & 96.6 & 114.2 & & 0.518 & 0.438 & \\
\hline $\mathrm{Ti}-\mathrm{CCM} \& \mathrm{Au}$ & 96.6 & 114.2 & 478 & 0.518 & 0.438 & 0.105 \\
\hline
\end{tabular}

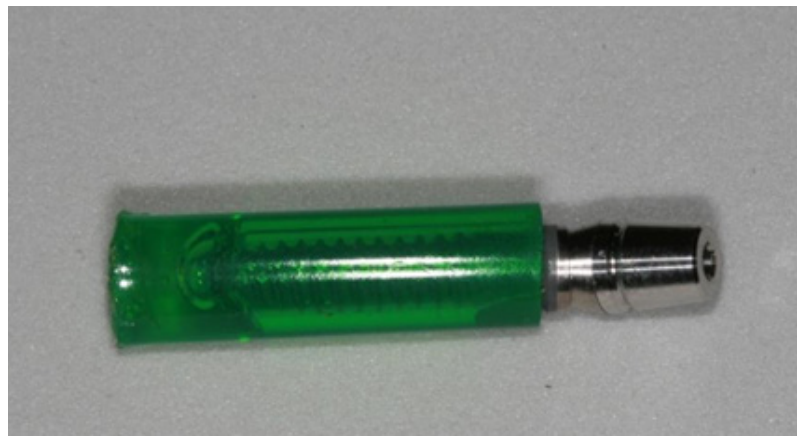

Figure I Implant with an artificial "peri-implant hose pipe" covering the whole osseointegration surface up to $0.5 \mathrm{~mm}$ underneath the machined neck of the fixture to imitate endosseous conditions; the apical part is sealed using $\mathrm{AGT}^{\mathrm{TM}}$-silicone glue.
All samples were placed in an electrolyte solution (volume 50ml) consisting $0.9 \% \mathrm{NaCl}$ (Isotonic saline 0.9\%: Braun, Melsungen, Germany) and $0.1 \mathrm{~mol} / 1$ lactic acid ((S)-Lactic acid: Caelo, Hilden, Germany) resulting in pH 5.2 (SevenGo Duo ${ }^{\circledR}$ : Mettler-Toledo, Gießen, Germany). Samples were always placed in the electrolyte without laminar contact to the container, and different samples were stored in the same electrolyte with maximum distance (about $50 \mathrm{~mm}$ ) to each other (Figure 2). The storage of the samples took place in a heating cabinet at a temperature of $37^{\circ} \mathrm{C}$. To provide some flow of the electrolyte solution, the tanks were tilted automatically by \pm 10 angular degrees every 3 minutes.

\section{DCP measurements}

Measurement of DCP differences between the samples and electrolyte solution were performed with the help of a multi-meter (Benning MM12 ${ }^{\circledR}$, Benning GmbH, Bocholt, Germany) with an 
inner electric resistance of $100 \mathrm{M} \Omega$ providing measuring accuracy of $0,01 \mathrm{mV}$. Measurements went on without virtual electric current flow, whereby the p-hold function of the device ensured recording of maximum data and excluded data from getting lost or being decreased by minimum leakage currents. So-called "pseudo-referenceelectrodes" out of $50 \mu \mathrm{m}$ gold-plated Au-Pt-Ru-aglets without electric resistance $(<1 \mu \Omega)$ were used to enable electrical contact to the samples and/or the electrolyte solution. ${ }^{5}$ These electrodes should prevent additional contamination of the electrolyte by metal ions. Before each DCP measurement, these electrodes were etched using concentrated phosphoric acid $(16 \mathrm{~mol} / \mathrm{l})$ and scaled to zero inside a pure control solution of the electrolyte. ${ }^{9}$ DCPs were determined by contact of one gold electrode with the sample that was lifted out of the electrolyte by about $5 \mathrm{~mm}$ and dried off at the contact area whereby the major part of the sample remained in the electrolyte. The test settings with a single sample (Ti-Ti or Ti-CCM) provided measurements of the potential difference between the sample and the electrolyte using a pseudo-reference-electrode (see above); in cases with two samples (Ti-Ti \& Au or Ti-CCM \& Au) DCP differences were ascertained between the particular samples and the electrolyte as well as between the different samples (Figure 3).

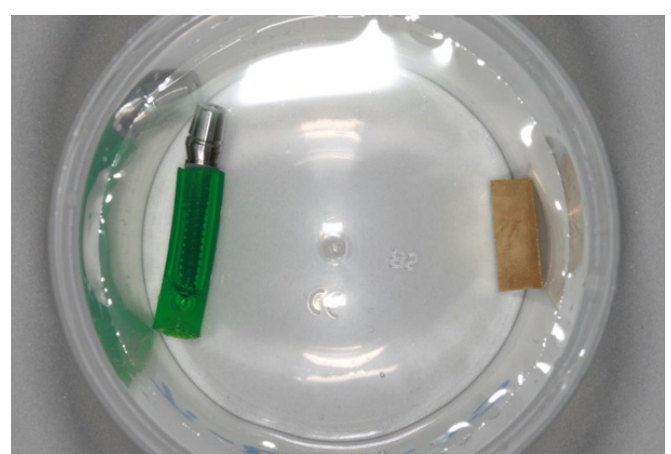

Figure 2 Implant and fine gold sample (test group Titanium-Titanium \& Fine Gold $=\mathrm{Ti}-\mathrm{Ti} \& \mathrm{Au}$ ) placed in the electrolyte solution with a distance of $5 \mathrm{~cm}$ having only punctiform contact to the electrolyte tank.

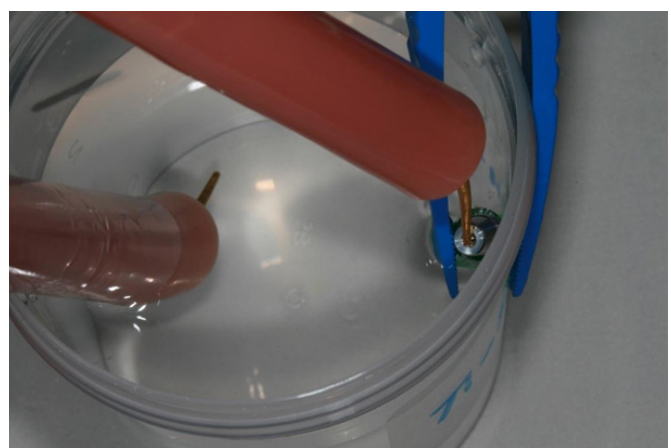

Figure 3 Direct current potential (DCP) measurement of implant probe against the electrolyte whereby the implant is lifted out of the solution and dried up at the measuring point.

DCP measurements were conducted on day 1, 4, 7 14, 21, 28, 35 and 38. For statistical reasons each measurement was performed trebly with time intervals of each 5 minutes.

\section{ICP-MS analysis}

According to ISO 10271 the electrolyte fluid was replaced after day $1,4,7$ and finally after day 35 . Concentrations of metal ions inside the used electrolyte were determined by ICP-MS (ICapQ: Thermo Fisher Scientific GmbH, Bremen, Germany) on day 1, 4, 7 and 38.
Samples were diluted 1:20 in $1 \% \mathrm{HNO}_{3}$ and analysed in kinetic energy discrimination-reaction mode. Measurements of each sample were carried out trebly and concentrations were calculated by Qtegra software (Thermo Fisher) using a five-point standard curve (multi element standard by ESI Elemental Service \& Instruments $\mathrm{GmbH}$, Mainz, Germany).

\section{Optical examination}

Optical examination of the sample surfaces was performed with the help of an apochromatic stereo-microscope (Zeiss Stemi $508^{\circledR}$, Zeiss, Oberkochem, Germany) using optical magnification of 1-36:1 before and after 5 as well as 26 weeks of immersion test period.

\section{Statistics}

Means for DCP and COR of each test group wereaveraged out of 15 single measurements.Data was checked for plausibility and evaluated statistically using ANOVA for multiple comparisons at a basis of $=0.05$ corrected according to Tukey (SPSS 25).

\section{Results}

\section{Electrostatic potentials}

After immersion of 2 weeks, DCPs of the different samples increased from an initial span of -100 to $-150 \mathrm{mV}$ to about -490 to $-580 \mathrm{mV}$. For all samples, differences between initial (day 1) and maximum (day 14) DCPs were significant $(\mathrm{p}<0.01)$. Combinations of Ti-Ti and Ti-CCM with fine gold revealed maximum DCPs during the first two weeks of immersion. After that DCPs continuously dropped to a common value of about $-450 \mathrm{mV}$, and significant differences of DCPs between the different material combinations (Table 1) could no longer be observed (Figure 4).

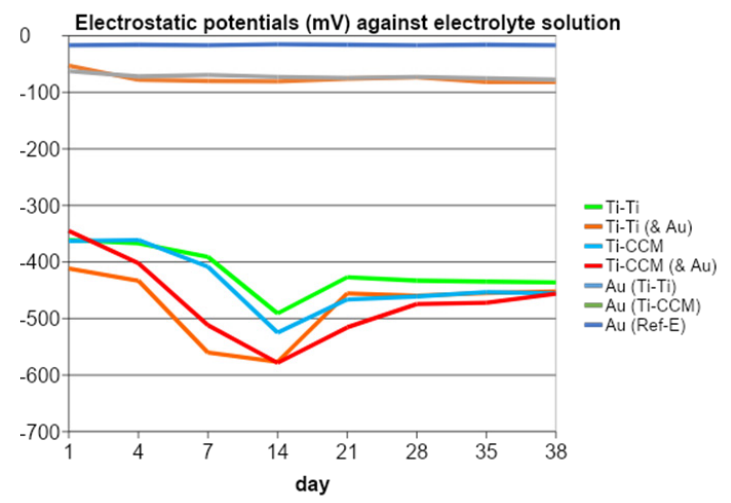

Figure 4 Direct current potentials (DCPs) of all samples ascertained between day $I$ and 38 of the immersion test whereby data is related to the potential of the electrolyte that is set to zero (abbreviations see in "Materials and Methods, ff: test groups"). The reference electrode fine gold=Au (Ref-E) had a constant DCP of $-16.2 \pm 0.8 \mathrm{mV}$ against the electrolyte. Generally, data was increased significantly at day $14(p=0.009-0.0027)$ for all samples; differences of DCP between test groups Ti-Ti and Ti-CCM were not significant $(p=0.55)$ at any time, those between group $\mathrm{Ti}-\mathrm{Ti}$ and $\mathrm{Ti}-\mathrm{Ti} \& \mathrm{Au}$ were significant at day I $(p=0.002)$, day $4(p=0.0014)$, day $7(p=0.0008)$, day $14(p=0.004)$, those between group Ti-CCM and Ti-CCM \& Au at day $4(p=0.003)$, day $7(p=0.001)$, day $14(p=0.007)$, and day $2 \mathrm{I}(\mathrm{p}=0.002)$.

\section{Corrosive reactions}

Multi-element-analysis (MEA) of the electrolyte demonstrated ion concentrations resulting from the sample materials as well as from other materials (Figure 5), the latter most likely representing 
contamination of implants or abutments by steel fabrication tools and through further processing. Typical examples of these contaminants are $\mathrm{Fe}, \mathrm{Cu}, \mathrm{Zn}, \mathrm{Sr}$, Mo etc.

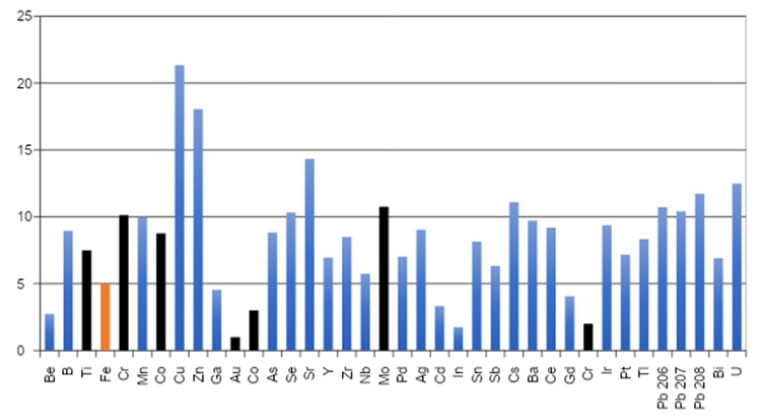

Figure 5 Logarithmic plot of multi-element analysis (MEA) of a sample containing all elements used for testgroup Titanium-Cobalt-ChromiumMolybdenum \& Fine Gold (Ti-CCM \& Au) showing black marked elements which were components of the samples and brown marked iron as a probative tracer for fabrication tools.

Focusing the alloying elements of the tested samples, high concentrations of these elements could be observed within the first week of immersion whereby titanium yielded superior COR rates $\left(2.00-12.06 \mu \mathrm{g} / \mathrm{cm}^{2}\right.$ per day). During the same period, COR of titanium was significantly $(\mathrm{p}=0.004)$ increased in samples containing non-precious alloys or gold compared to pure titanium samples. Maximum titanium COR was found in samples with non-precious alloys and gold as well.

After 38 days of immersion, titanium still showed superior COR $\left(0.66-1.37 \mu \mathrm{g} / \mathrm{cm}^{2}\right.$ per day) for all tests and a less significant $(\mathrm{p}=0.042)$ differences between the samples with and without $\mathrm{Co}, \mathrm{Cr}$ and $\mathrm{Mo}$ could be confirmed (Table 2).

Among all non-precious abutment materials, only cobalt reveals maximum concentration on the first day of immersion (Ti-CCM \& Au: $0.593 \mu \mathrm{g} / \mathrm{cm}^{2}$ per day). After 38 days, it nearly disappeared or dropped to minimum values $\left(0.013-0.026 \mu \mathrm{g} / \mathrm{cm}^{2}\right.$ per day).

COR of iron was used as a tracer for tool materials and showed maximum values during the first week of immersion. Maximum iron COR $\left(1.09-1.15 \mu \mathrm{g} / \mathrm{cm}^{2}\right.$ per day) was seen in samples consisting of titanium abutments combined with or without gold. Samples with non-precious components revealed iron COR of $0.66-0.82 \mu \mathrm{g} / \mathrm{cm}^{2}$ per day. These results must be considered as a sign of contamination caused by fabrication of implants and ready-made abutments, as iron is not a component part of the alloys used (Ti grade 4 or Co-Cr28Mo).

Table 2 Concentrations of dissociated main components of the different samples $\left(\mu \mathrm{g} / \mathrm{cm}^{2}\right.$ per day) at days I-38 of the immersion test, and iron as a trace element (means \pm S.D.). Missing data signifies immeasurably minimum concentrations. Abbreviations see in "materials and methods, ff: test groups"

\begin{tabular}{|c|c|c|c|c|c|c|}
\hline Test group & day & $\mathrm{Ti}$ & $\mathrm{Cr}$ & Co & $\mathrm{Au}$ & $\mathrm{Fe}$ \\
\hline \multirow[t]{4}{*}{$\mathrm{Ti}-\mathrm{Ti}$} & 1 & & $0.066 \pm 0.016$ & $0.056 \pm 0.007$ & & $1.094 \pm 0.132$ \\
\hline & $2-4$ & $3.885 \pm 0.302$ & $0.06 \pm 0.013$ & & & $0.81 I \pm 0.092$ \\
\hline & $5-7$ & $4.158 \pm 0.840$ & $0.049 \pm 0.011$ & & & $0.697 \pm 0.170$ \\
\hline & $36-38$ & $0.662 \pm 0.059$ & & & & \\
\hline \multirow[t]{4}{*}{ Ti-Ti \& Au } & 1 & $4356 \pm 0.537$ & $0.055 \pm 0.014$ & $0.072 \pm 0.010$ & $0.003 \pm 0.001$ & $1.151 \pm 0.253$ \\
\hline & $2-4$ & $5.809 \pm 0.331$ & $0.052 \pm 0.016$ & & $0.002 \pm 0.001$ & $0.675 \pm 0.027$ \\
\hline & $5-7$ & $5.661 \pm 0.407$ & $0.041 \pm 0.012$ & & $0.002 \pm 0.001$ & $0.532 \pm 0.029$ \\
\hline & $36-38$ & $0.639 \pm 0.029$ & & & $0.002 \pm 0.001$ & \\
\hline \multirow[t]{4}{*}{ Ti-CCM } & 1 & $9.656 \pm 0.984$ & $0.072 \pm 0.024$ & $0.473 \pm 0.183$ & & $0.578 \pm 0.074$ \\
\hline & $2-4$ & $8.841 \pm 1.103$ & $0.064 \pm 0.015$ & $0.094 \pm 0.012$ & & $0.657 \pm 0.068$ \\
\hline & $5-7$ & $7.586 \pm 0.707$ & $0.04 \pm 0.008$ & $0.07 \pm 0.009$ & & $0.426 \pm 0.043$ \\
\hline & $36-38$ & $1.376 \pm 0.124$ & & $0.026 \pm 0.004$ & & \\
\hline \multirow[t]{4}{*}{ Ti-CCM \& Au } & 1 & $|0.797 \pm| .40 \mid$ & $0.076 \pm 0.027$ & $0.593 \pm 0.096$ & $0.002 \pm 0.001$ & $0.787 \pm 0.082$ \\
\hline & $2-4$ & $12.064 \pm 1.163$ & $0.032 \pm 0.009$ & $0.053 \pm 0.010$ & $0.003 \pm 0.001$ & $0.824 \pm 0.127$ \\
\hline & $5-7$ & $10.934 \pm 1.334$ & $0.027 \pm 0.008$ & $0.042 \pm 0.008$ & $0.002 \pm 0.001$ & $0.509 \pm 0.092$ \\
\hline & $36-38$ & $1.318 \pm 0.137$ & & $0.013 \pm 0.011$ & $0.002 \pm 0.001$ & \\
\hline
\end{tabular}

\section{Surface discoloration}

Optical check of the outside and inside surfaces of the samples did not yield distinct signs of corrosive discoloration after 5 or 26 weeks of immersion. Nevertheless, all titanium surfaces revealed an insignificant grey-yellowish and mat tan compared to the other non-precious material (Figure $6 \&$ 7). Fine gold samples, however, showed brown-grey-violet discoloration that could be easily removed by acidification (Figure 8 ). 


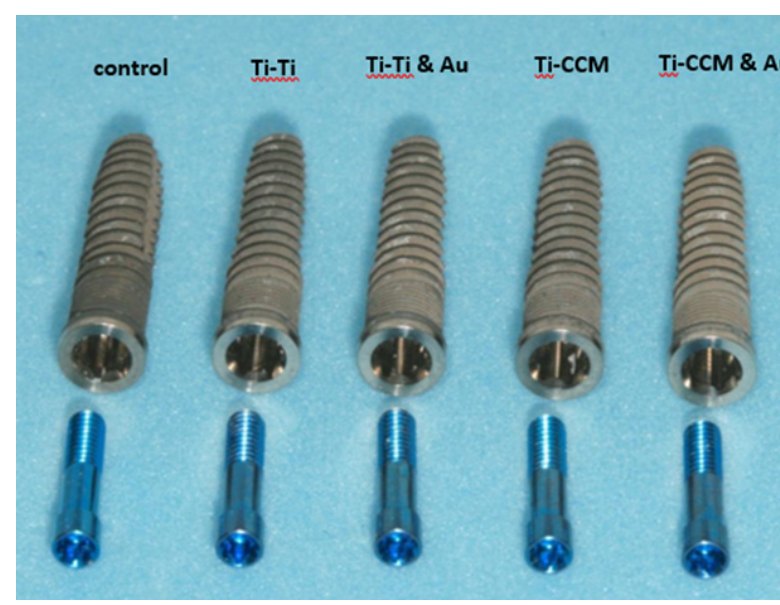

Figure 6 Each one titanium base and SIM 5 cone for any test group after 26 weeks of immersion in lactic acid compared to an untreated control.Titanium as well as Cobalt-Chromium-Molybdenum (CCM) abutments or cones do not reveal visible discoloration of the outer and inner surface (abbreviations see in "Materials and Methods, ff: test groups").

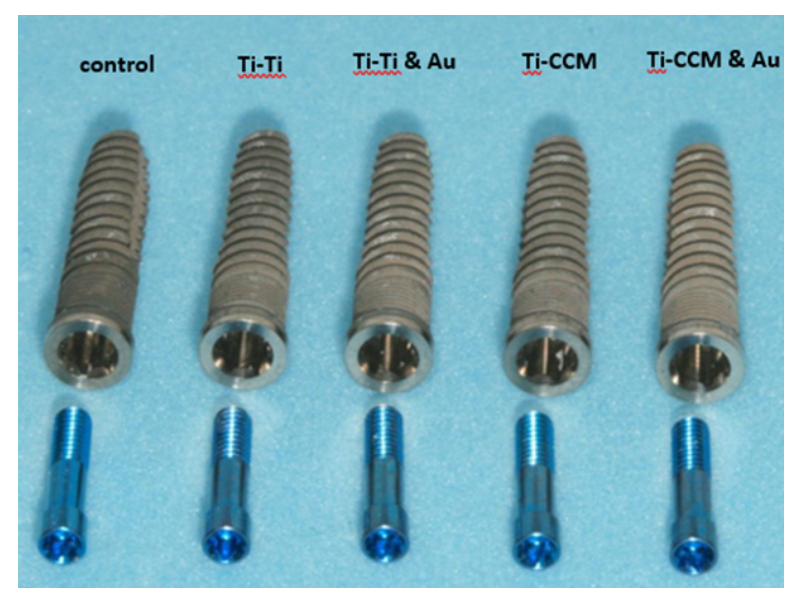

Figure 7 Fixtures of the different test groups after 26 weeks of immersion in lactic acid. The osseointegration surface of all treated implants is slightly brighter compared to the control but no visible discoloration exists at the inner surface of the fixtures (abbreviations see in "Materials and Methods, ff: test groups").

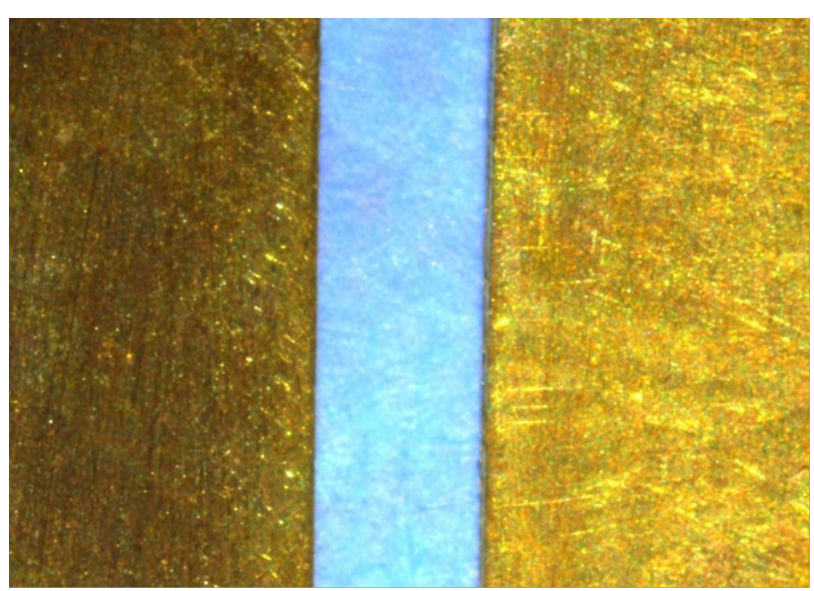

Figure 8 Fine gold samples (magnification 36:I); left after 26 weeks of immersion, and right after acidification using NEACID ${ }^{\circledR}$ (Degudent, Hanau, Germany).

\section{Discussion}

This study was performed to investigate corrosive processes on titanium implants in combination with different metallic abutments. To this aim, an in-vitro corrosion assay was employedthat was optimized for the detection of electrochemical ion release. For this purpose, implant abutments made of titanium or non-precious CCM (Co-CrMo) alloys combined with or without fine gold (galvano technique) were objected to in-vitro corrosion tests heeding a study protocol according to DIN EN ISO $10271 .{ }^{14}$ For the chemical composition of the electrolyte solution, the main chemical parameters of saliva and biofilms were considered and standardized.Hereafter, a $\mathrm{pH}$-value of 5.2 appears small but is not unusual on metal surfaces underneath biofilms. ${ }^{13,15}$

Dynamic effects which have a possible additional impact on corrosion like attrition of the elements, damages of the passivated surfaces of the samples, changing $\mathrm{pH}$ or deformations were discounted, though. Admittedly, an alternating load test would have inferred the risk of uncontrolled contamination of the immersion fluid.

The theoretical consideration of the problem is relativized through the use of a different electrolyte, though, since its redox potential is not the same as that of hydrogen normal electrode. ${ }^{16}$ In the present investigation, the redox potential of the lactic acid electrolyte used was determined experimentally with the help of a calomel electrode and showed data of $+1.68 \pm 0.12 \mathrm{~V}$. The result was that all metals and alloys tested including fine gold exhibited negative potential values against the electrolyte solution used. Therefore, the electrolyte as well as fine gold, both demonstrating relatively constant electric potentials, could be used as so-called "help or reference electrodes". ${ }^{17,18}$ To work with calomel or hydrogen normal-electrodes would have complicated the experimental setup much more or contaminated the electrolyte with additional metal ions leading to interferences in the determination of corrosion of the test materials according to ISO 10271. Moreover, measurements using calomel- or hydrogen-electrodes are not feasible in the oral cavity which considerably complicates any comparison of the present data with clinical findings that are generally ascertained with the help of special gold electrodes complying with the German Medical Devices Act. ${ }^{5,19}$

The open and almost electroless measurement of electrostatic potentials between the implant and abutment samples on the one hand and the electrolyte solution or corroded fine gold samples on the other revealed a nearly linear increase of DCP between day 4 and 14 scoring maximum data of $0.49-0.58 \mathrm{~V}$ which was diminished to about $0.45 \mathrm{~V}$ at day 38 . These results associate with statements of patients, whereby metallic flavour is often sensed during the first two weeks following exposition of the fixtures, and disappears later on. ${ }^{13}$

ICP-MS data shows high rates of corrosion of titanium grade 4, although high corrosion resistance of titanium is frequently pointed out. The present study, however, clearly indicates increased electrochemical solubility of titanium as compared to the other metals and alloys tested, using lactic acid immersion at $\mathrm{pH}$ 5.2. Comparable $\mathrm{pH}$-values are common underneath a biofilm with bacterial activity, which is a fact considered also by DIN EN ISO $10271 .{ }^{14,20}$ Therefore, corrosion generated by biofilms is also called "biocorrosion", whereby metabolism of bacteria leads to a decrease of $\mathrm{pH}$ that enables a better electric conductibility of the electrolyte medium and as a result, leads to increased corrosion rates. ${ }^{15}$ 
Solubility of titanium also depends on the concomitance of other metallic substances in the same electrolyte, which can have an impact on the redox potential of titanium according to their own redox properties. This effect becomes important when different metals have a conductive connection, i.e. a local cell is assembled. The more elements are combined in this connection, the more confusing the mathematical handling of single corrosive processes will become. ${ }^{13}$ Nevertheless, the results reveal that the existence of fine gold samples inside the electrolyte without electric connection to titanium as well as CCM abutments on titanium fixtures lead to an increase of titanium corrosion. In this connection, the combination of titanium, nonprecious alloys and gold, a so-called "metal-mix", generates superior corrosion of titanium implant material. ${ }^{5}$

After showing maximum values during the first 2 weeks, both corrosion parameters DCP and COR were significantly diminished at the end of the observation period of 38 days. This could be interpreted as a sign of galvanic passivation of the sample surfaces which were not treated with functional abrasion or changes of the $\mathrm{pH}$ in this study. For all combinations with other alloys, COR of titanium fell short of $1.4 \mu \mathrm{g} / \mathrm{cm}^{2}$ per day that cannot be identified as a pathologic concentration, since there is no recognized critical threshold value to date. Nevertheless, recent investigations of Jacobi-Gresser ${ }^{21}$ and Olmedo $^{22}$ indicate that even subtoxic doses of titanium particles or ions can lead to pathologic reactions either locally or systemically. This can cause chronical inflammatory systemic diseases or alterations of the neural system. Possible local and systemic pathological effects are increasingly discussed. ${ }^{12,23,24}$

With regard to COR of non-precious elements, it has to be noted that a non-measurable part of the ions concerned could have precipitated as oxides or chlorides at the surface of the cathode, i.e. the fine gold sample which could be observed microscopically as surface discolouration. Thus, non-water-soluble chemical compounds of cobalt, chromium and molybdenum could have been eluded from analytical determination using ICP-MS that is only able to detect soluble or dissociated components. On the contrary, dissociation of $\mathrm{Co}, \mathrm{Cr}$ and Mo could be increased by mistake, since these are also part of tool alloys necessary for fabricating the implant and abutment surfaces and leading to a contamination of the sample material. Therefore, $\mathrm{Fe}$ as a non-integral part of all samples tested was used as a tracer substance to provide evidence that dissolved substances must not necessarily be originated from the implant or abutment alloy (Figure $5 \&$ Table 2).

The yellowish discolouration of the titanium samples can be interpreted by oxidation of the surfaces resulting in golden-yellow Ti(IV)-oxide $\left(\mathrm{TiO}_{2}\right)$. Also, imaginable could be the synthesis of titanium-lactate or -chloride in presence of the electrolyte used, however, both of them are water-soluble and therefore these would not be deposited on the samples. Less probable is the precipitation of gold onto the titanium samples, because these are anodes in the electrolyte solution. Moreover, yellowish discolouration of titanium samples could be also observed in experimental setups without gold samples. Therefore, it can be concluded that passivation of titanium with the help of Ti(IV)-oxide takes some time in the present conditions, and is not a result of a "rapid self-healing process". ${ }^{25}$

The present investigation yields a protective layer developed at the surface of the samples that shields it from further corrosion after a couple of weeks. This self-protecting mechanism also occurs in cases of chromium-alloyed steel or Co-Cr-Mo alloys in the same manner, which could be relevant for the increasing stability of the non- precious alloy against corrosion in the present study. Also, DCPs of the samples caused by electro-chemical processes scoring maximum absolute data during the first 2 weeks of immersion reveal a reduction along with increasing passivation of the sample surfaces. After 2-5 weeks, only poor COR could be ascertained for titanium and very poor or non-measurable COR could be seen for all other metals and alloys even in the presence of non-precious metals or fine gold.

Whether the current in-vitro data may be translated to conditions in vivo will have to be investigated in future studies. In a clinical test arrangement, there are additional parameters like abrasion and shunt faults as well as additional electric fields between the different metallic components or varying $\mathrm{pH}$-values which could influence the results and could not be considered sufficiently in the present invitro study. Nevertheless, clinical investigations confirm the range of oral DCPs and re-emphasize the impact of a combination of different metals or alloys on oral health. ${ }^{5,13,26-28}$ But for all that, the present investigation clearly points out that dissociationof titanium continues to a measurable extent even on day 38 , and yields maximum data among all metals tested at any point of time.

Finally, pros and cons of the different materials used for implant abutments and prosthetic devices applied should be deliberated. On the one hand, titanium reveals a relatively high corrosive solubility combined with mediocre mechanical properties. On the contrary, CCM alloys show much better long-term stability combined with negligible corrosive solubility of cobalt inside weak acid electrolyte like human saliva. ${ }^{10}$ Within the limitations of this in-vitro study, there are no electrochemical objections either to the use of non-precious alloys of the type Co-Cr-Mo (CCM) or fine gold for implant abutments and implant supported dentures neglecting an increased dissociation of titanium and some other alloying elements during the first week of immersion. However, a material mix of fine gold, titanium and CCMalloys should be avoided to prevent from increased dissociation of titanium. Therefore, a mechanical as well as a clinical examination of CCM abutments and screws attached to titanium fixtures should be performed.

\section{Funding}

None.

\section{Acknowledgments}

None.

\section{Conflicts of interest}

The authors have no conflicts of interest relevant to this article.

\section{References}

1. Ali Z, Baker SR, Shahrbaf S, et al. Oral health-related quality of life after prosthodontic treatment for patients with partial edentulism: A systematic review and meta-analysis.J Prosthet Dent. 2018;121(1):59-68.

2. Analytical Chemistry. In: Lide DR, editor. CRC Handbook of Chemistry and Physics. 84 $4^{\text {th }}$ ed. Boca Raton: CRC Press; 2003, p. 8-22.

3. Buedinger L, Hertl M. Immunologic mechanisms in hypersensitity reactions to metal ions: an overview. Allergy.2000;55(2):108-115.

4. Wang Y, Dai S. Structural basis of metal hypersensitivity. Immunol Res. 2013;55(1-3):83-90.

5. Niedermeier W. OralerGalvanismus - Ursachen und Folgen. ZWR. 2015;124(12):578-84 
6. Ullmann K. Leukoplakia caused by electrogalvanic current generated in the oral cavity. Wien KlinWochenschr.1932;45:840-844.

7. Lain ES. Electrogalvanic lesions of the oral cavity produced by metallic dentures. J Amer Med Assoc. 1933;100:717-720.

8. Banoczy J, Roed-Petersen B, Pindborg JJ, et al. Clinical and histologic studies on electrogalvanically induced oral white lesions. Oral Surg Oral Med Oral Pathol. 1979;48(4):319-323.

9. Korraah A, Odenthal M, Kopp M, et al. Induction of apoptosis and up-regulation of cellular proliferation in oral leukoplakia cell lines inside electric field. Oral Surg Oral Med Oral Path Oral Radiol. 2012;113(5):644-654.

10. Titanium Grade 4 \& Cobalt CCM (data sheets). L Klein SA, Biel/Bienne (Switzerland).

11. Herbst D, Dullabh H, Sykes L, et al. Evaluation of surface characteristics of titanium and cobalt chromium implant abutment materials. SADJ. 2013;68(8):350-356.

12. Huesker K. Pathomechanisms and laboratory diagnostic evidence of acute and chronic metal exposure.ZWR. 2017;126(12):608-614.

13. Noumbissi S, Scarano A, Gupta S. A Literature Review Study on Atomic Ions Dissolution of Titanium and Its Alloys in Implant Dentistry. Materials (Basel). 2019;12(3):368.

14. DIN EN ISO 10271:2011-10, Dentistry - Corrosion test methods for metallic materials. Berlin: Beuth; 2011. p. 1-36.

15. Little B, Wagner P, Mansfeld F. An overview of microbiologically influenced corrosion.ElectrochimActa.1992;37(12):2185-2194.

16. Kaesche H. Corrosion of metals: physico-chemical principles and current problems. 3rd ed. Berlin: Springer; 2011, p. 122-144.

17. Ives DJG, Janz GJ, King CV. Reference Electrodes. Theory and Practice. J Electrochem Soc.1961;108(11):246-247.
18. Kahlert H. Reference electrodes. In: Scholz F, editor. Electroanalytical methods. 2nd ed. Berlin: Springer; 2010. p. 291-308.

19. German Medical Devices Act (german medical devices act). BGB1; 2002. p. 3393-3404.

20. Schlafer S. pH landscapes in a novel five-species model of early dental biofilm. PLoS One. 2011;6(e25299):1-11.

21. Jacobi-Gresser E. Genetic and immunological risk factors for implantations. ZWR. 2016;125(12):612-617.

22. Olmedo DG, Nalli G, Verdú S, et al. Exfoliative cytology and titanium dental implants: a pilot study.J Periodont. 2013;84(1):78-83.

23. Makihira S, Mine $\mathrm{Y}$, Nikawa $\mathrm{H}$, et al. Titanium ion induces necrosis and sensitivity to lipopolysaccharide in gingival epithelial-like cells. ToxicolIn Vitro. 2010;24:1905-1910.

24. Wachi T, Shuto T, Shinohara Y, et al. Release of titanium ions from an implant surface and their effect on cytokine production related to alveolar bone resorption. Toxicology. 2015;327:1-9.

25. Wang L, Yu H, Wang Ket al. Local Fine Structural Insight into Mechanism of Electrochemical Passivation of Titanium. ACS Appl Mater Interfaces. 2016;8(28):18608-18619.

26. Apaza-Bedoya K, Tarce M, Benfatti CAM, et al. Synergistic interactions between corrosion and wear at titanium-based dental implant connections: A scoping review. J Periodont Res. 2017;52(6):946-954.

27. Wirz J, Jaeger K, Schmidli F. Metal ions in tissue. Quintessence.1993;44:1833-1843.

28. Guindy JS, Schiel H, Schmidli F, et al. Implant loss due to corrosion in the marginal gap area of implant-supported dentures. Implantology. 2005;13(2):163-170. 